\title{
O Pro-Am como \\ estratégia jornalística no Twitter: \\ Apontamentos para discussão
}

\author{
Vivian Belochio* \\ Gabriela Zago**
}

Resumo: Este trabalho tem por objetivo discutir as possibilidades do movimento Pro-Am como estratégia jornalística no Twitter. O estudo tem caráter exploratório e toma como base para a discussão as diferentes manifestações do jornal digital Zero Hora.com no microblog. Foram percebidas práticas que apontam para a colaboração entre amadores e profissionais na construção e na circulação de notícias, demonstrando indícios de que o Twitter pode vir a se integrar ao processo jornalístico como um todo.

Palavras-chave: Jornaliso digital; Pro-Am; Twitter.

\section{Pro-Am as a journalistic strategy on Twitter: Notes for discussion}

\begin{abstract}
This paper aims to discuss the possibilities of Pro-Am as a journalistic strategy on Twitter. The study has an exploratory approach and the discussion is based on the different expressions by Zero Hora.com on Twitter. We observed some social network practices that point to a collaboration between amateurs and professionals on the construction and circulation of news, what demonstrates evidences that Twitter can be integrated into journalistic process as a whole.
\end{abstract}

Keywords: Digital journalism; Pro-Am; Twitter.
Artigo recebido em: 20 de abril de 2009 Aprovado em: 2 de outubro de 2010

* Doutoranda em Comunicação e Informação pela UFRGS. Bolsista CAPES. Jornalista, mestre em Comunicação Midiática pela UFSM. Membro do Grupo Jornalismo Digital da UFSM e do Laboratório de Interação Mediada por Computador (LIMC/UFRGS).

vicabel@terra.com.br

** Mestranda do Programa de PósGraduação em Comunicação e Informação da Universidade Federal do Rio Grande do Sul (PPGCOM) UFRGS). Bolsista CAPES. Membro do Laboratório de Interação Mediada por Computador (LIMC).

gabrielaz@gmail.com 


\section{Introdução}

1 todo o momento surgem novas ferramentas e serviços web, com propostas e propósitos diferenciados. Esses espaços são apropriados de formas distintas pelos indivíduos, que os utilizam com finalidades diversas. Alguns destes meios podem trazer implicações para a prática jornalística. Esse é o caso do Twitter, cuja apropriação para a circulação de informações o tornou propício para que os meios jornalísticos também buscassem se utilizar desse espaço para a extensão dos seus conteúdos (JENKINS, 2008), bem como dos seus contextos de atuação. Entretanto, por se tratar de uma ferramenta relativamente nova, não se tem ainda um conjunto de regras e de procedimentos a seguir, o que torna o ambiente favorável para que novas e interessantes apropriações emirjam, a partir das práticas observadas.

Com base nesse cenário, este trabalho tem por objetivo discutir o movimento Pro-Am, descrito por Anderson (2006) como a parceria entre profissionais e amadores com o auxílio da comunicação digital, como um processo possível a partir da apropriação feita pelos veículos noticiosos no Twitter. O estudo traz os resultados de uma análise exploratória de caráter qualitativo a partir das práticas observadas no perfil de Zero Hora.com no Twitter. Conforme discutiremos ao longo do trabalho, o jornal digital parece se utilizar de estratégias "launch and learn" (SAAD, 2003) em sua aproximação com a ferramenta.

$\mathrm{O}$ artigo está dividido em duas partes, seguidas de apontamentos para discussão. Em um primeiro momento, discorre-se sobre o Twitter enquanto um espaço em que se pode observar um novo padrão de troca de informações. A seguir, são discutidas as estratégias jornalísticas visualizadas no Twitter, com destaque para o Pro-Am. Ao final, são levantados alguns pontos para discussão, na forma de considerações preliminares, de caráter não conclusivo, sobre a relação possível entre Pro-Am, jornalismo e Twitter.

\section{O Twitter como espaço para um novo padrão de troca de informações}

O Twitter é uma ferramenta de microblog criada em 2006 pela Obvious. A proposta do site é que se responda à pergunta "O que está acontecendo?" ("What's happening?") em até 140 caracteres ${ }^{1}$. Pode-se atualizar e receber atualizações pela web, pelo celular (web móvel ou SMS) ou por aplicativos derivados criados a partir da $\mathrm{API}^{2}$ do Twitter. Tais possibilidades são inerentes ao

\footnotetext{
"O Twitter foi criado com a pergunta inicial "What are you doing?" (o que você está fazendo?), a fim de possibilitar a intervenção descompromissada dos seus adeptos sobre as suas próprias experiências cotidianas. As apropriações do espaço, contudo, ultrapassaram tal proposta, resultando na troca dinâmica de metainformações com links para meios jornalísticos e para blogs, entre outras páginas. Atualmente, o questionamento inicial do Twitter é "What's happening?" (o que está acontecendo?). 2 Segundo Zago (2009, p.4), "a API são pacotes de programação de dados, que permitem diversas recombinações por parte de desenvolvedores, o que pode culminar na criação de ferramentas derivadas (o que inclusive pode resultar em novas maneiras de se atualizar e receber atualizações) e também na criação de mashups".
} 
formato dos micoblogs. De acordo com Primo (2008, p.46), o microblogging é um fenômeno recente que "vem ganhando força na blogosfera". Além das características do formato blog em versão simplificada, eles também apresentam duas características adicionais, que os identificam: a mobilidade e a arquitetura aberta de informações (ZAGO, 2009).

Desde 2006, a ferramenta tem crescido mais a cada ano, sendo que um relatório elaborado pela Sysomos ${ }^{3}$ em junho de 2009 aponta que, considerando-se o crescimento do Twitter até então, 72,5\% dos usuários da ferramenta tinham começado a usá-la nos primeiros meses de 2009. No Brasil não foi diferente. A ferramenta tornou-se mais popular no começo de 2009, quando passou a receber atenção da mídia tradicional ${ }^{4}$.

Embora a ferramenta tenha sido criada mais voltada para uso pessoal, aos poucos novas formas de utilização foram surgindo. Como afirma Primo (2008, p.46), "em pouco tempo, muitos novos usos ultrapassaram a proposta inicial do Twitter". O espaço passou a ser utilizado para a conversação, o compartilhamento de informações e de links, e até mesmo para campanhas publicitárias e para o jornalismo (MISCHAUD, 2007; JAVA et al., 2007; HONEYCUTT e HERRING, 2009; HUBERMAN, ROMERO e WU, 2009). Essas utilizações decorrem em grande parte tanto da estrutura e da arquitetura aberta da ferramenta (a possibilidade de atualizações curtas também contribui para isso) quanto do fato de ela ter sido apropriada como um site de rede social (RECUERO \& ZAGO, 2009). De fato, para Orihuela (2007), a ferramenta pode ser compreendida não só como rede social, mas também como um misto entre blog, rede social e mensageiro instantâneo ${ }^{5}$.

Para boyd e Ellison (2007), um site de rede social pode ser caracterizado por possibilitar aos seus usuários

(1) construir um perfil público ou semi-público em um sistema interligado, (2) articular uma lista de outros usuários com os quais eles compartilham uma conexão, e (3) ver e cruzar suas listas de conexões e aquelas feitas por outros no sistema (BOYD \& ELLISON, 2007, on-line) ${ }^{6}$

O caráter de rede social do Twitter decorre do fato de que cada interagente ${ }^{7}$ pode ser representado por um perfil, o qual reúne suas atualizações em ordem cronológica inversa, e pela possibilidade de poder interagir com os demais a partir desse perfil. Além disso, as conexões entre os interagentes - a lista de seguidos e seguidores de cada um - são exibidas publicamente.

\footnotetext{
${ }^{3}$ http://www.sysomos.com/insidetwitter/

${ }^{4}$ De acordo com o Ibope, 5 milhões de brasileiros acessaram o Twitter no mês de junho de 2009, o que representa $15 \%$ do total de internautas do país.

${ }^{5}$ A existência de usuários que "colecionam" amigos e a busca por reputaçãoo na rede, entre outros fatores, são considerados marcas de que o microblog tenha sido apropriado como rede social.

"Tradução de "(1) construct a public or semi-public profile within a bounded system, (2) articulate a list of other users with whom they share a connection, and (3) view and traverse their list of connections and those made by others within the system" (BOYD \& ELLISON, 2007, online).

7 Conforme Primo (2007), "receptor, usuário, utilizador e novo espectador são termos infelizes no estudo da interação, pois deixam subentendido que essas figuras estão à mercê de alguém hierarquicamente superior, que é quem pode tomar de fato as decisões" (2007, p. 149). Por essa razão, o termo interagente é utilizado, subentendendo a ação do internauta no processo interativo.
} 
Por conta de seu caráter de rede social, o Twitter possibilita que as informações possam circular de forma mais ágil. Uma informação pode ser retwittada, ou seja, repassada na íntegra para outros contatos (BOYD, GOLDER $\&$ LOTAN, 2010). Ela também pode ser linkada ou apresentada junto a uma tag, que possibilita o posterior resgate do histórico associado a uma determinada informação e seus desdobramentos, a partir da sua ferramenta de busca. Outro elemento importante para a informação no Twitter é o fato de que seu sistema de buscas permite realizar pesquisas cujos resultados são apresentados em tempo real - algo que outros buscadores, como o Google, não costumam oferecer como recurso padrão.

Embora os interagentes tenham se apropriado da ferramenta para realizar coberturas minuto a minuto de eventos, retweets, empregar tags para comentar e acompanhar fatos e acontecimentos, dentre outros usos, em geral a apropriação feita pelas empresas jornalísticas na ferramenta costuma se restringir à mera reprodução do conteúdo de feeds RSS no formato manchete + link, muitas vezes a partir de ferramentas que automatizam esse processo (como no caso do uso do Twitterfeed) (ZAGO, 2009).

Mesmo assim, é importante notar que, aos poucos, a presença dos veículos jornalísticos no Twitter foi crescendo. De uma ferramenta

O Twitter

\section{tornou-se mais}

popular no começo de 2009, quando passou a receber atenção da mídia tradicional inicialmente criada para finalidades teoricamente "fúteis" (é interessante lembrar que a pergunta inicial do microblog era, até 2009, "O que você está fazendo?"), o microblog tem se consolidado como um sistema que estabelece um diferente padrão para trocas de informações entre os interagentes.

A própria evolução do Twitter se deu na forma de uma estratégia "pure play" (SAAD, 2003). Saad (2003, p.123) explica que pure play são as "empresas com base na internet, que recorrem à tecnologia digital e ao uso da web como principal meio de comunicação e interação para atuar no mundo virtual". De acordo com a autora, os negócios que seguem este modelo surgiram "a partir do boom da internet, sem vinculação a mídias tradicionais" (SAAD, 2003, p.122). Tais operações são marcadas pela criação e pela disponibilização de novos espaços na rede, com formatos voltados à ambiência digital. São exemplos as empresas/estratégias que não possuem representação fora da web, ou seja, apareceram com a intenção de atuar no ciberespaço e de conquistar o público que navega pela rede8.

Com base nas afirmações anteriores, entende-se que o Twitter pode ser considerado um modelo pure play. $\mathrm{O}$ microblog foi criado para a troca de dados e para a interação possíveis na web. Isso implica o apoio em tecnologias específicas que permitem o acesso à ferramenta. Portanto, trata-se de um espaço exclusivo das redes digitais, que introduz diferentes formas de interação entre os seus adeptos.

Avançando um pouco mais, percebe-se que a criação de distintas modalidades comunicacionais em espaços como o Twitter também pode ser compreendida como iniciativa pure play. Sua apropriação pelos interagentes foi, aos

\footnotetext{
${ }^{8}$ O termo pure significa, entre outras coisas, puro, sem misturas, autêntico, genuíno. Já a palavra play
remete a jogo, brincadeira, diversão, e, mesmo, a peça de teatro ou brinco. A expressão "pure play",

${ }^{8}$ O termo pure significa, entre outras coisas, puro, sem misturas, autêntico, genuíno. Já a palavra play
remete a jogo, brincadeira, diversão, e, mesmo, a peça de teatro ou brinco. A expressão "pure play", originada do e-business, refere-se a iniciativas novas, originais que envolvem novos jogadores.
} O Pro-Am como estratégia jornalística no Twitter 
poucos, levando à configuração atual da ferramenta. Recursos hoje próprios do sistema, como Replies e direcionamento de mensagens para um determinado interagente por @, o emprego de hashtags para organizar a informação, ou os retweets não existiam quando da criação do Twitter. Eles surgiram a partir de apropriações sucessivas dos interagentes, que passaram, coletivamente, a adotar tais convenções para facilitar a comunicação entre si. A partir dessas apropriações, a própria ferramenta passou a incorporar esses recursos. Segundo Primo (2008, p.46), práticas como o tagging foram desenvolvidas "como forma de facilitar a recuperação de mensagens sobre um mesmo tema". O pesquisador observa que "o hashtag, como foi batizado, é um fenômeno emergente, um 'protocolo social' compartilhado pelas pessoas que conhecem o processo” (2008, p.46).

Assim, enquanto meio nativo da rede, o Twitter tem sido constantemente apropriado e moldado pelos indivíduos, pelas organizações e pelas instituições como o jornalismo. O microblog está se afastando progressivamente de sua proposta inicial de ser um espaço para compartilhar informações pessoais, originalmente em resposta à pergunta “O que você está fazendo?”, para se tornar um meio de comunicação mais complexo, em que diferentes atores indivíduos, empresas, veículos de comunicação - podem interagir de diversas formas e em tempo real. Possivelmente em decorrência disso é que foi modificada a sua própria pergunta inicial, que em 2009 passou a ser "O que está acontecendo?".

Talvez por essa peculiaridade de apropriação é que os veículos jornalísticos tenham a tendência de ingressar na ferramenta utilizando-se da estratégia descrita por Saad (2003) como "launch and learn". Referindo-se à adaptação das empresas jornalísticas tradicionais às tendências da web no início do milênio, a pesquisadora explica que os conglomerados midiáticos lançavam os seus sites na rede "para depois aprender na prática e com a reação do mercado acerca das modificações e adequações do serviço informativo digital e, por fim, a definição de uma estratégia a posteriori” (SAAD, 2003, p.123). Acredita-se que esta experiência vem se repetindo atualmente no Twitter. É notória a iniciativa dos jornais de referência ${ }^{9}$ de estar na ferramenta, ainda que não se tenha uma estratégia bem definida de como usá-la. A apropriação vai se moldando aos poucos, enquanto se aprende a lidar e a interagir com o novo meio.

\section{Estratégias jornalísticas no Twitter}

A manifestação cada vez mais frequente da mídia jornalística no Twitter mostra que a ferramenta tornou-se importante entre as estratégias desenvolvidas pelos meios noticiosos digitais. Diante disso, questionamos se o microblog é considerado apenas mais um recurso capaz de atrair novos leitores. Quais os motivos da movimentação dos conteúdos jornalísticos para o Twitter? Os jornais digitais têm objetivos definidos no processo de disponibilização dos seus conteúdos no microblog?

\footnotetext{
${ }^{9}$ De acordo com Berger (1996, p. 1), "o jornal de referência pretende testemunhar o mundo, produzindo um discurso universal e objetivável". Ele é vinculado à chamada imprensa tradicional. Neste trabalho, utilizamos o termo jornal de referência seguindo a linha de pensamento da autora.
} 
Uma das razões que podem levar os jornais de referência à apropriação do microblog é o fato de ele ter se transformado num elemento do chamado "composto informacional midiático" (PRIMO, 2008). Trata-se do "conjunto de informações disseminadas tecnologicamente por meios de comunicação que servem para a atualização individual sobre notícias" (PRIMO, 2008, p.46). Em outras palavras, o composto é formado pelos conteúdos difundidos pelos meios informativos com os quais um cidadão tem contato no seu cotidiano. O sujeito consome informações diversas em vários tipos de mídia no seu dia a dia. A partir disso, interpreta tais dados e os incorpora nas suas rotinas, conforme as suas necessidades.

O Twitter é um dos meios através dos quais os indivíduos constroem as suas impressões sobre os fatos e sobre a realidade. Visto isso, acaba se tornando uma importante via para a atuação dos meios noticiosos. Assim, tais meios realizam o movimento chamado por Jenkins (2008, p.45) de extensão. De acordo com o autor, trata-se de um efeito da convergência marcada pela expansão estratégica dos conteúdos jornalísticos para "diferentes sistemas de distribuição". E mais uma marca de que o processo de convergência não se refere apenas à mistura de imagens, sons e textos na composição das informações que aparecem na rede. Como afirma Jenkins (2008, p.27), ela também envolve o "fluxo de conteúdos através de múltiplos suportes midiáticos", a "cooperação entre múltiplos mercados midiáticos" e o "comportamento migratório dos públicos dos meios de comunicação, que vão a quase qualquer parte em busca das experiências de entretenimento que desejam".

Entre os resultados mais evidentes da extensão, destaca-se a alteração da apresentação das informações jornalísticas na rede. O movimento obriga os meios a adaptarem os seus conteúdos às normas das outras mídias nas quais estão se expondo. Isso acontece quando as notícias são adaptadas para aparecer em redes sociais como o Facebook, ou no Google Buzz, por exemplo. Nesses espaços as informações jornalísticas adquirem formatos distintos. Isso também acontece no Twitter. Apenas chamadas com até 140 caracteres podem ser exibidas no meio. Por conta disso, é comum observar, no microblog, a exposição de manchetes jornalísticas curtas seguidas de links.

A título de exemplo são apresentados, neste artigo, casos baseados nas experiências do jornal Zero Hora.com no Twitter. Os dados foram coletados a partir de observação realizada no Twitter e em Zero Hora.com entre novembro de 2009 e abril de 2010. Os referidos conteúdos foram colhidos aleatoriamente e utilizados para ilustrar características que demonstram como o meio vem utilizando o microblog.

A figura a seguir traz o primeiro exemplo:

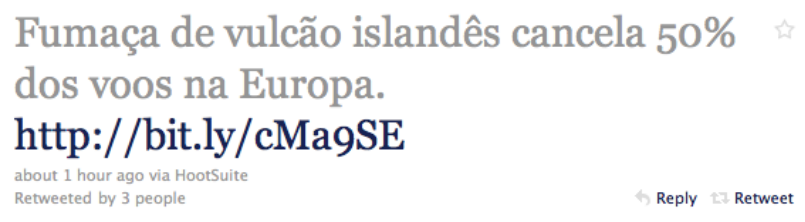

zerohora

Zero Hora

Figura 1 -É comum encontrar posts como o do jornal "Zero Hora": chamadas curtas com links para as notícias. 
A figura 1 ilustra o formato recorrente da manifestação dos meios jornalísticos no Twitter. A chamada de Zero Hora.com, meio gaúcho de referência mantido pelo Grupo RBS, exibe a informação principal com um link que direciona os navegadores interessados ao site onde a notícia, na sua estrutura completa, está disponível.

A imagem que segue traz uma demonstração da integração do meio jornalístico com as linguagens criadas na ferramenta:

\section{Obrigada pelo \#FF @paulostudio2002 @docthiago@dullim @LeticiaRaythz @JesseRodrigues

half a minute ago via HootSuite $\quad$ Reply 27 Retweet

\section{zerohora}

Zero Hora

Figura 2 - Zero Hora.com agradece as indicações recebidas no Follow Friday.

$\mathrm{Na}$ figura 2, percebe-se a utilização feita pelo jornal digital de uma tendência criada pela coletividade no microblog. A mensagem postada no perfil agradece aos interagentes que sugeriram Zero Hora.com no Follow Friday (\#ff). Tratase de uma prática comum entre os interagentes na ferramenta, que consiste na indicação de perfis para se seguir no Twitter todas as sextas-feiras. O perfil de Zero Hora.com não só costuma ser indicado por vários interagentes, como também, nessa ocasião, o jornal agradeceu tais indicações, demonstrando o seu conhecimento sobre o funcionamento do sistema, em uma prática que não costuma ser observada em outros perfis de organizações jornalísticas.

Outra recente apropriação de Zero Hora.com do Twitter aparece na figura 3.
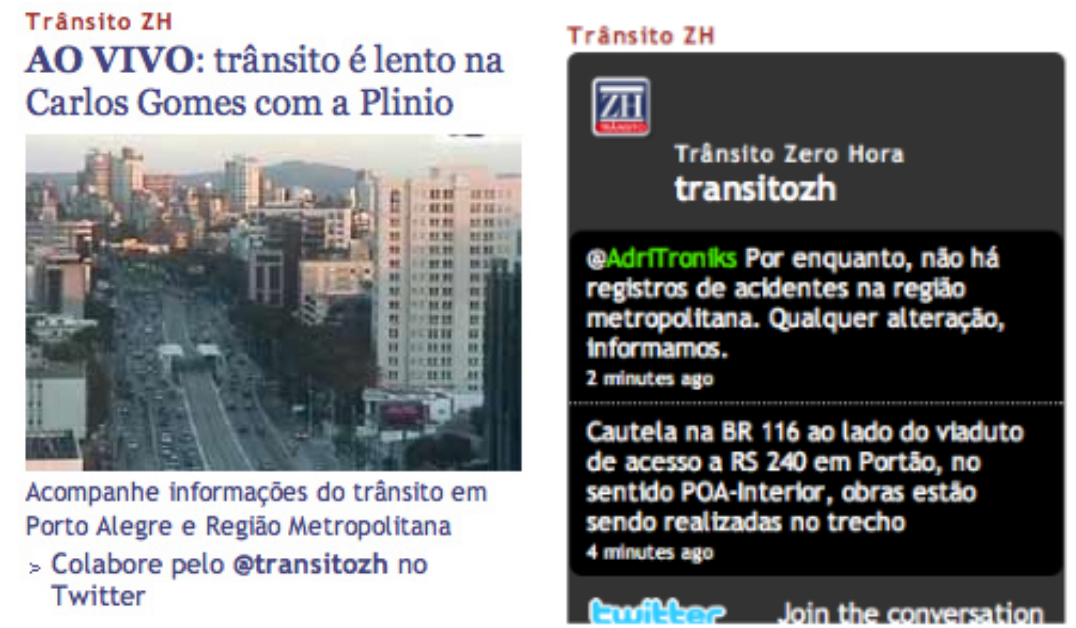

Figura 3 - Ocasiões em que o perfil Trânsito ZH do Tritter recebeu destaque na capa do site Zero Hora.com.

O jornal Zero Hora.com criou um perfil no Twitter no começo de 2010 apenas para cobrir informações relativas ao trânsito em Porto Alegre e na região metropolitana. Não são raras as vezes em que essas atualizações são exibidas na capa do site de Zero Hora.com. Muitas vezes, solicita-se que os interagentes colaborem com informações através do microblog. Noutras, o próprio 
veículo retwitta informações cedidas pelos interagentes sobre o trânsito, ou fornece informações a partir da solicitação de determinados interagentes.

\section{A possibilidade do Pro-Am como estratégia jornalística no Twitter}

Com o passar do tempo, os veículos noticiosos perceberam outras possibilidades de utilização do Twitter. Assim, seguindo a lógica do launch and learn destacada anteriormente, experimentaram novas estratégias, capazes de potencializar não apenas a sua popularidade no espaço, mas a própria interação com as suas fontes de informação. Além de postar chamadas utilizando recursos como as hashtags e os retweets, linguagens criadas no microblog pelos interagentes, os meios jornalísticos iniciaram um processo de troca de informações com os internautas.

Relacionamos tal iniciativa com o processo chamado por Anderson (2006) de Pro-Am. Significa o trabalho em parceria entre profissionais e amadores a partir das possibilidades abertas na rede. Conforme o autor, o termo foi criado pelo centro de altos estudos inglês conhecido como Demos, a partir da "confirmação de uma teoria básica sobre o funcionamento do universo" com o auxílio de amadores. A internet é um dos elementos que tornou o processo possível. A partir da experiência, inaugurou-se a "época em que profissionais e amadores trabalham lado a lado” (ANDERSON, 2006, p.58).

O Pro-Am é um fenômeno que pode estar acontecendo nos meios jornalísticos que disponibilizam seções colaborativas nos seus produtos na rede (BELOCHIO, 2009). Ele pode ser observado quando os jornais digitais solicitam o envio de informações, fotografias e vídeos sobre determinados eventos que não conseguem cobrir de maneira abrangente e instantânea. A partir dessa ação, os veículos noticiosos buscam ampliar a qualidade e a quantidade de informações e detalhes sobre os acontecimentos com os quais trabalham, mediante a ajuda recebida do público amador.

Acreditamos que a troca mais intensa entre jornalistas e amadores também pode ser visualizada no Twitter. A seguir, serão descritos alguns exemplos, a partir de dados coletados de Zero Hora.com no mês de novembro de 2009.

A próxima imagem mostra um aspecto que remete à ideia do Pro-Am:

$$
\begin{aligned}
& \text { zerohora Participe da cobertura de Zero Hora: sofreu com o } \\
& \text { \#apagão? Mande seu relato. http://bit.ly/1JNvD2 } \\
& 19 \text { minutes ago from bit.ly }
\end{aligned}
$$

Figura 4-Zero Hora.com solicitou colaborações para a cobertura de apagão, em novembro de 2009.

A figura 4 mostra tweets realizados em novembro de 2009 pelo jornal digital Zero Hora.com. A imagem 'A' indica uma chamada simples sobre o apagão elétrico que atingiu doze Estados brasileiros no dia 10 de novembro do mesmo ano. Já a figura 'B' destaca um convite ao público, por meio da seguinte 
composição: "Participe da cobertura de Zero Hora: sofreu com o \#apagão? Mande seu relato".

É notória a busca de colaborações dos leitores com relação ao evento em destaque nos tweets de Zero Hora.com. Consideramos a ação do jornal digital um exemplo interessante de como o Pro-Am pode ser viabilizado a partir da apropriação do Twitter.

A próxima figura destaca outro caso, que mobilizou diversas reações por parte dos interagentes:

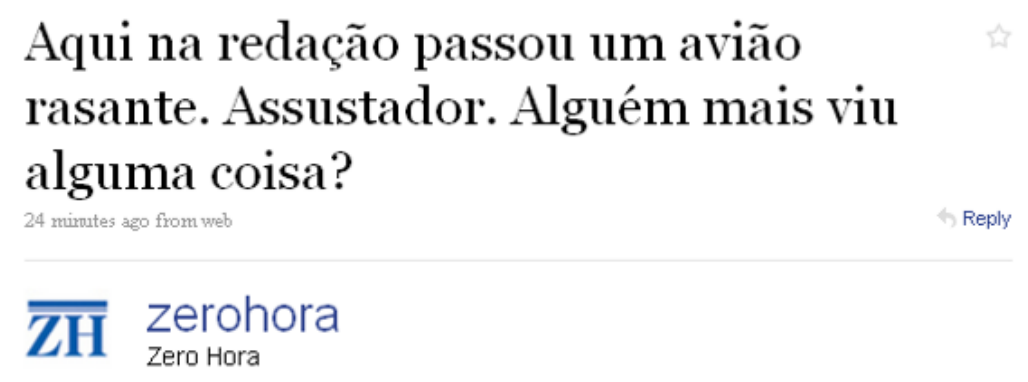

Figura 5 - Zero Hora.com pede informações sobre um fato.

A figura 5 destaca a pergunta "Aqui na redação passou um avião rasante. Assustador. Alguém mais viu alguma coisa?". A questão foi direcionada por Zero Hora.com aos seus seguidores no Twitter, com a provável intenção de buscar relatos mais concretos sobre o evento.

Nos 20 minutos que seguiram a essa atualização do jornal digital no Twitter, foram observadas 62 reações. Quatro tweets foram feitos pelo próprio perfil de Zero Hora.com. Dois destes tweets consistiam, além da pergunta citada no parágrafo anterior, em respostas do meio aos interagentes, na forma de Replies, e uma quarta mensagem buscava trazer esclarecimentos preliminares sobre o fato.

Um total de 34 tweets eram Replies para @zerohora. Destes, 15 procuravam responder à pergunta mencionando a localização dos seus autores e 19 procuravam responder à pergunta, porém sem mencionar a localização. Aspecto interessante é que os próprios interagentes tomaram a iniciativa de informar a partir de qual região da cidade estavam se pronunciando.

Ao todo, 20 das 62 reações eram constituídas por retweets das mensagens postadas originalmente por Zero Hora.com. Enquanto 11 dessas mensagens eram meras reproduções do que o perfil do jornal digital havia dito, nove iam além e traziam, também, comentários e impressões pessoais dos interagentes sobre o fato. Ainda, outras quatro mensagens mencionavam o perfil de Zero Hora.com, porém sem direcionar a mensagem ao perfil ou reproduzir seu conteúdo. Também foi observado um caso em que um interagente sugeriu, via Reply, que Zero Hora.com ligasse para o aeroporto para obter informações. A equipe do jornal digital respondeu, pelo Twitter, que a Infraero não teria ainda informações, dando retorno ao interagente na própria ferramenta.

Embora os interagentes, naquele momento, não tenham ajudado no esclarecimento do fato, suas contribuições constituíram um conjunto de impressões em tempo real sobre o acontecimento, vindo a estabelecer um relacionamento aparentemente próximo com o jornal de referência. Duas notícias sobre o caso foram disponibilizadas em Zero Hora.com, ambas no dia 15/11/2009. Uma 
delas merece destaque. Na matéria "Avião em voo rasante assusta moradores da capital" , foram publicadas algumas das reações coletadas via Twitter. $\mathrm{Na}$ ocasião, Zero Hora.com relatou o temor dos leitores com relação ao evento e ressaltou que a sua busca por informações acerca do acontecimento sucedeu após solicitações efetuadas pelo público. O veículo também destacou ter recebido mais de 50 tweets sobre o fato, incorporando, no corpo da matéria, três postagens feitas por seus seguidores no microblog.

As características constatadas a partir da breve análise aqui realizada permitem a inferência de que é possível, para os meios noticiosos que se apropriam do Twitter, estabelecer contato com as fontes jornalísticas de maneira diferente das formas tradicionais. Ou seja, o processo de produção das notícias conta com um novo recurso, que pode ser capaz de complementar determinadas coberturas mediante a colaboração de amadores.

\section{Considerações finais}

Ao se analisar, em caráter exploratório, o perfil de Zero Hora.com no Twitter, foram percebidos alguns indícios da existência de uma produ-

O Zero Hora.com é um exemplo interessante de como o ProAm pode ser viabilizado com o Twitter ção Pro-Am a partir do microblog, na medida em que trocas realizadas na ferramenta podem vir a suscitar a produção de materiais para outros meios. Observou-se uma forma de interação distinta com as fontes, possibilitada pelo uso da rede social através da experimentação, ou seja, por meio da estratégia launch and learn. A partir de testes realizados na ferramenta, os meios jornalísticos podem descobrir diferentes maneiras para conquistar popularidade e conseguir um bom retorno do público, como vem acontecendo em Zero Hora.com.

Conforme foi observado, é possível que se abra mais uma porta para que o Pro-Am aconteça, embora não necessariamente através do próprio Twitter. Notam-se iniciativas de Zero Hora.com no sentido de buscar colaborações de amadores, como no caso de realizar perguntas, convites e de receber respostas e sugestões de pautas através da ferramenta. Embora não tenham sido observadas contribuições diretas na produção de notícias do jornal digital, as interações realizadas no microblog podem contribuir ativamente para o processo jornalístico como um todo, servindo para aproximar os interagentes ao jornal de referência.

Assim, considera-se que a interação no Twitter pode vir a integrar o jornalismo enquanto processo, como uma extensão do processo jornalístico, embora muitas vezes não seja integrada ao seu principal produto - a notícia. Tem-se, através do Twitter, a possibilidade de realizar um debate público instantâneo, ainda que com tamanho limitado a cada atualização, em que participam o jornal de referência e os interagentes, em constante colaboração. Trata-se de um processo diferente, que demonstra a possibilidade do alargamento das áreas de atuação dos meios jornalísticos nas redes digitais. Isso indica a necessidade de observar o fenômeno de forma mais aprofundada em outros meios que fazem uso do microblog. 


\section{Referências bibliográficas}

ANDERSON, C. The Long Tail. Londres: Random House, 2006.

BELOCHIO, V. Jornalismo colaborativo em redes digitais: estratégia comunicacional no ciberespaço. O caso de Zero Hora.com. Dissertação (Mestrado em Comunicação Midiática). Universidade Federal de Santa Maria. Santa Maria, 2009.

BERGER, C. Campos em confronto: jornalismo e movimentos sociais. As relações entre o movimento sem terra e a Zero Hora. Tese (Doutorado em Comunicação). Universidade de São Paulo. São Paulo, 1996.

BOYD, d.; ELLISON, N. Social network sites: Definition, history and scholarship. Journal of Computer-Mediated Communication. v. 13, n. 1, 2007. Disponível em http://jcmc.indiana.edu/vol13/issue1/boyd.ellison.html. Acesso em 20 jan. 2009.

BOYD, d.; GOLDER, S.; LOTAN, G. Tweet, Tweet, Retweet: conversational aspects of retweeting on Twitter. HICSS-43. Kauai, HI: IEEE Press, 2010. HUBERMAN, B., ROMERO, D. \& WU, F. Social Networks that matter: Twitter under the microscope. First Monday, Vol 14, N. 1. 5 jan. 2009. Disponível em http://firstmonday.org/htbin/cgiwrap/bin/ojs/index.php/fm/article/view/2317/2063. Acesso em 20 jan. 2009.

HONEYCUTT, C. \& HERRING, S.C. Beyond microblogging: Conversation and collaboration via Twitter. HICSS-42. Los Alamitos, CA: IEEE Press, 2009. Disponível em http://ella.slis.indiana.edu/ herring/honeycutt. herring.2009.pdf. Acesso em 20 jan. 2009.

JAVA, A.; SONG, X.; FININ, T.; TSENG, B. Why We Twitter: Understanding Microblogging Usage and Communities. Procedings of the Joint 9th WEBKDD, 2007.

JENKINS, Henry. Cultura da Convergência. São Paulo: Aleph, 2008.

MISCHAUD, E. Twitter: Expressions of the Whole Self. Dissertação (Mestrado). London School of Economics, Department of Media and Communications, Londres, 2007.

ORIHUELA, J.L. Twitter y el boom del microbloggng. Educ.ar. Educación y TIC. Argentina, 22 nov. 2007. Disponível em http://portal.educ.ar/debates/e ducacionytic/super-sitios/twitter-y-el-boom-del-microblo.php. Acesso em 22 nov. 2007.

PRIMO, A. A cobertura e o debate público sobre os casos Madeleine e Isabella: encadeamento midiático de blogs, Twitter e mídia massiva. Galáxia, São Paulo, n.16, p.43-59, 2008.

PRIMO, A. Interação Mediada por Computador. Porto Alegre: Sulina, 2007.

RECUERO, R.; ZAGO, G. Em busca das "redes que importam": redes sociais e capital social no Twitter. Líbero, São Paulo, v.12, n.24, p. 81-94, 2009. RECUERO, R. Redes Sociais na Internet. Porto Alegre: Sulina, 2009. SAAD, Beth. Estratégias para a Mídia Digital: Internet, informação e comunicação. São Paulo: Editora SENAC, 2003.

ZAGO, G. O Twitter como suporte para produção e difusão de conteúdos jornalísticos. Ciberlegenda, Niterói, n.21, p.13, 2009. 